\title{
Recent Progress Toward Understanding the Molecular Biology of Von Recklinghausen Neurofibromatosis
}

\author{
David H. Gutmann, MD, PhD, and Francis S. Collins, MD, PhD
}

\begin{abstract}
The gene for von Recklinghausen neurofibromatosis (NF1) was recently identified by positional cloning and found to code for a large, ubiquitously expressed protein. This protein has both structural and functional similarity to a family of proteins with guanosine triphosphatase-activating properties, involved in the regulation of the protooncogene ras. One of the postulated functions of the NF1 gene product may relate to its ability to regulate ras-mediated cell proliferation. Selective pharmacotherapy directed at downregulating ras may be of benefit to patients with NF1.
\end{abstract}

Gutmann DH, Collins FS. Recent progress toward understanding the molecular biology of Von Recklinghausen neurofibromatosis. Ann Neurol 1992;31:555-561

Neurofibromatosis type 1 (NF1), or von Recklinghausen neurofibromatosis, is one of the most common autosomal dominant disorders in humans. It is characterized by abnormalities affecting tissues derived primarily, but not exclusively, from the neural crest, including multiple neurofibromas, cafe-au-lait spots, axillary freckling, Lisch nodules of the iris, distinct bony lesions, and optic nerve gliomas [1]. The NF1 locus is unusual in that the spontaneous mutation rate is estimated to be 100-fold higher than the usual rate for a single locus; 30 to $50 \%$ of cases represent new mutations [1]. The risk of malignancy is also increased, especially for neurofibrosarcomas and brain tumors [2].

Early linkage analysis demonstrated that the locus for NF1 resides on chromosome 17 [3]. The identification of two patients with chromosome 17 translocations facilitated the identification of the gene for NF1 [4-6]. Further chromosomal and cDNA walking culminated in the determination of the entire NF1 coding sequence [7].

\section{The NF1 Gene}

The gene for NF1 spans approximately $300 \mathrm{~kb}$ of genomic DNA and encodes an approximately $13-\mathrm{kb}$ messenger RNA with an open reading frame of 8,454 nucleotides [7] (Fig 1). The predicted protein product is 2,818 amino acids with a predicted molecular mass of $327 \mathrm{kd} \mathrm{[7].} \mathrm{Forty-nine} \mathrm{exons} \mathrm{and} \mathrm{two} \mathrm{alternatively}$ spliced mRNA isoforms have been identified. An un- expected finding was the discovery of three genes embedded within one intron of the NFI gene. These three genes, OMgp [8], EVI2A [9], and EVI2B [10], are transcribed in the opposite orientation as the NF1 gene and their contribution to the disease is uncertain. In fact, the phenotype of disease in patients with deletions of OMgp, EVI2A, and EVI2B is the same as that of patients with point mutations in the NF1 gene [4-6], indicating that the embedded genes may not affect the usual manifestations of the disease. Two of these genes, EVI2A and EVI2B, are human homologues of putative mouse protooncogenes that may play a role.in the pathogenesis of murine myeloid tumors. Juvenile chronic myelogenous leukemias have been reported to occur more frequently in NF1 patients than in the general population, suggesting a possible role for these genes in NF1-related myeloid malignancies [2]. However, thus far, there is no evidence for mutations in these genes in NF1 patients or significant differences in the abundance of EVI2A and EVI2B mRNA in NF1 patients. Of additional interest is the OMgp gene, encoding an abundant myelin protein (oligodendrocyte-myelin glycoprotein), which was previously thought to be a good candidate for the NF1 gene, given its role in central nervous system cell-cell communication [11]. Again, there is no evidence to directly implicate the OMgp gene in the pathogenesis of NF1.

The mRNA for NF1 is ubiquitously expressed, suggesting that the neural crest predominance of abnor-
From the Departments of Neurology, Internal Medicine, and Human Genetics, Howard Hughes Medical Institute, The University of Michigan Medical School, Ann Arbor, MI.

Received Oct 23, 1991, and in revised form Nov 15 and Nov 25. Accepted for publication Nov 26, 1991.
Address correspondence to Dr Gutmann, 4570 MSRB 2, Howard Hughes Medical Institute, The University of Michigan, Ann Arbor, M1 48109-0650. 


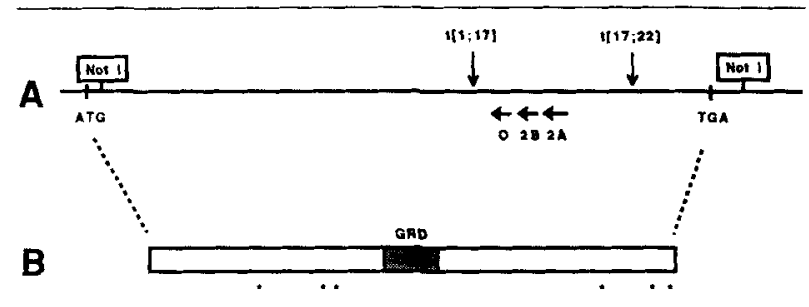

Fig 1. Schematic representation of the NF1 gene. (A) The genomic map of the NF1 locus depicts the two Not I restriction enzyme recognition sites separated by approximately $300 \mathrm{~kb}$ of $D N A$. The relationship between the initiation codon (ATG), the termination codon (TGA), and the Not I sites is illustrated. The pasitions of the translocation breakpoints from two NF1 patients $(t, 1: 17)$ and $t(17 ; 22)$, which facilitated the identification of the NF1 gene, are included. The embedded genes, OMgp (O), EVI2B (2B), and EVI2A (2A), are shown as being transcribed from the opposite DNA strand as the NF1 gene. (B) The neurofibromin protein is depicted with the GAPrelated domain (GRD) and the six potential serinelthreonine phosphorylation sites (*).

malities in NF1 is not the result of tissue-specific expression of NF1 mRNA [4, 7]. Homologues of the NF1 gene have been identified in all vertebrate animals examined [12]. Analysis of the predicted amino acid sequence suggests that the NFl gene product is a cytoplasmic protein without a transmembrane-spanning region. In addition, six potential serine/threonine phosphorylation sites and a single tyrosine phosphorylation site, important in signal transduction molecules, have been identified (see Fig 1).

Sequence analysis of the full-length cDNA reveals sequence similarity between a small portion of the NF1 gene (NF1-guanosine triphosphatase [GTPase]activating protein [GAP]-related domain [NF1GRD]) and a family of GAPs in mammals and yeast (IRAl, IRA2) [13]. The entire NF1 protein was originally termed NF1 GAP-related protein (NF1GRP) to underscore the relationship between the NF1GRD, mammalian GAP [14], and the yeast IRA1 and IRA2 genes [15]. The consensus name for the NF1 gene product is now neurofibromin. These GAP proteins accelerate the hydrolysis of ras-guanosine triphosphate (GTP) to ras-guanosine diphosphate (GDP), converting the protooncogene prorein, ras, from the active to the inactive form [16]. Although the precise role of ras in mammalian cells is not clear, it appears to play significant roles in growth factor-mediated proliferation and neoplasia (see Funcrion of neurofibromin section below). The ability of the NF1GRD to function as a GAP-related protein in vivo and in vitro was demonstrated independently by three groups [17-19].

\section{The NF1 Protein}

The protein product of the NF1 locus has recently been identified $([20,21]$, Basu TN, Gutmann $\mathrm{DH}$,

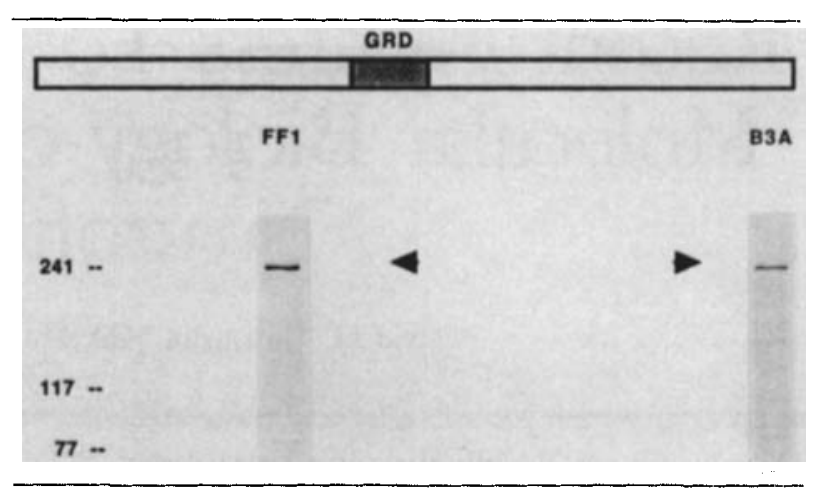

Fig 2. Immunoprecipitation of neurofibromin using two different rabbit antisera ( $F F 1, B 3 A$ ) directed against distinct regions of the protein. The relationship of these antisera epitopes to the full length neurofibromin molecule is illustrated. These antisera were generated as previously described (120), Gutmann $D H$, unpublished results). Human HeLa cells radiolabeled with ${ }^{35} \mathrm{~S}$ metbionine overnight were lyzed and immunoprecipitated before separation by $7.5 \%$ sodium dodecyl sulfate-polyacrylamide gel electrophoresis and autoradiograpby for 3 days. The positions of the molecular weight markers in kd are shown at the left margin. Neurofibromin migrates as a 250-kd protein (arrow).

Collins FS, and Downward J, unpublished data). Using antibodies generated against fusion proteins and synthetic peptides, a unique $250-\mathrm{kd}$ protein was found in all tissues and cell lines examined ([20]; Fig 2). Immunoblot analysis of adult mouse tissues demonstrated the highest levels of expression in brain, kidney, and spleen [20]. The difference between the predicted molecular mass $(327 \mathrm{kd})$ and the observed size $(250 \mathrm{kd})$ is most likely due to anomalous migration and not to protein processing (Gutmann $\mathrm{DH}$, unpublished re-sults). This protein was localized to the cytoplasm by two different methods, differential centrifugation (Basu TN, Gutmann DH, Collins FS, and Downward J, unpublished data) and glycerol gradients [21]. Indirect immunofluorescence using antibodies generated against neurofibromin likewise demonstrated cytoplasmic localization (Gregory PE, Gutmann DH, Boguski M, Wood DL, and Collins FS, unpublished data). Neurofibromin appears to colocalize with microtubules in all cell types examined by immunofluorescence and biochemical purification, suggesting that neurofibromin is intimately associated with cytoskeletal elements (Fig 3).

\section{Function of Neurofibromin}

Undifferentiated cells contain the genetic capacity for rapid growth during embryonic development as well as differentiation into specific tissues. In addition to genes that facilitate growth and differentiation (protooncogenes), cells also contain genes that code for proteins that inhibit these processes. The genes that downregulate the expression of growth-promoting factors 

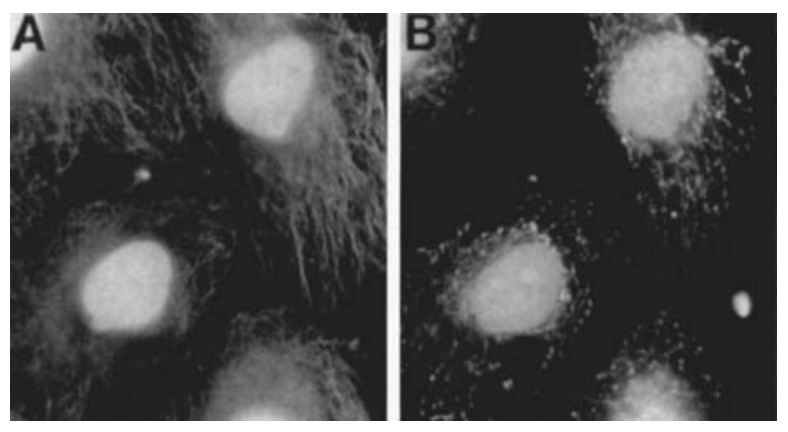

Fig 3. Immunofluorescence of fibroblast cells demonstrating the colocalization of neurofibromin and microtubules. Kangaroo rat fibroblast (PTK) cells were incubated with rbodamine-labeled anti- $\beta$-tubulin ( $A$ ) and fluorescein-labeled anti-neurofibromin (B3A) antiserum (B). The $\beta$-tubulin monoclonal antibody stains microtubules.

are termed tumor suppressor genes [22]. Progression to malignancy, or transformation, can therefore arise as a result of activating mutations in genes that facilitate cell growth (e.g., protooncogenes) or inactivating mutations in genes that inhibit these processes (tumor suppressor genes). Evidence for the existence of these tumor suppressor genes is based in part on the genetic predisposition of certain individuals to some pediatric malignancies; fusion of normal cells with certain pediatric tumor cells leads to suppression of the tumorigenic phenorype and chromosomal loss often accompanies the return to the neoplastic state. Tumor formation or transformation occurs when these genes are inacti- vated, implying that their normal function is to limit cell proliferation. This mechanism, originally known as the Knudson hypothesis, has been most thoroughly demonstrated for the retinoblastoma gene [23]. The known tumor suppressor genes are listed in the Table.

In an inherited cancer syndrome, like NF1, each somatic cell in an affected individual has one normal copy of the NF1 gene; the other copy is inherited as a mutant gene. However, in the abnormal neural crest tissues, the one remaining normal NF1 gene is hypothesized to undergo somatic mutation to render both copies nonfunctional ( $[23]$; Fig 4). The loss of both normal NF1 genes in neurofibromas has not yet been formally demonstrated. However, recent evidence has shown that both NF1 genes are indeed disrupted in some neurofibrosarcoma cell lines (Legius E, unpublished results).

It is appealing to postulate that neurofibromin acts as a tumor suppressor by regulating some intracellular protein essential for cell growth and proliferation (Fig 5). One such protein, ras, has been shown to be important in growth factor-mediated cell proliferation. Overexpression of ras in fibroblasts leads to transformation, whereas anti-ras antibody injection blocks these events $[24,25]$. It has been established that a small portion of neurofibromin expressed alone (NF1GRD) can inactivate ras by accelerating ras GTP hydrolysis [17-19]. If the major function of neurofibromin in cells is to downregulate ras, then loss of neurofibromin through mutation would lead to cell proliferation and transformation. Examination of some neurofibrosarcoma cell lines has demonstrated elevated

Tumor Suppressor Genes

\begin{tabular}{|c|c|c|c|c|}
\hline $\begin{array}{l}\text { Tumor } \\
\text { Suppressor Gene }\end{array}$ & $\begin{array}{l}\text { Chromosomal } \\
\text { Location }\end{array}$ & Site of Action & $\begin{array}{l}\text { Proposed } \\
\text { Mechanism }\end{array}$ & Human Tumors \\
\hline Retinoblastoma & $13 q 14$ & Nucleus & Transcription factor & $\begin{array}{l}\text { Retinoblastoma; } \\
\text { osteosarcoma; } \\
\text { lung, breast, } \\
\text { prostate, bladder } \\
\text { melanoma }\end{array}$ \\
\hline Wilms' tumor & $11 \mathrm{p} 13$ & Nucleus & Transcription factor & $\begin{array}{l}\text { Nephroblastoma, } \\
\text { hepatoblastoma }\end{array}$ \\
\hline $\begin{array}{l}\text { Mutated in colon } \\
\text { cancer (MCC) }\end{array}$ & $5 q 21$ & $?$ & $?$ & Colon cancer \\
\hline $\begin{array}{l}\text { Deleted in colon } \\
\text { cancer (DCC) }\end{array}$ & $18 \mathrm{q} 21$ & $\begin{array}{l}\text { Cell } \\
\text { membrane }\end{array}$ & $\begin{array}{l}\text { ? Cellular adhesion } \\
\text { molecule }\end{array}$ & Colon cancer \\
\hline $\begin{array}{l}\text { Adenomatous } \\
\text { polyposis coli (APC) }\end{array}$ & $5 q 21$ & Cytoplasm & $?$ & Colon cancer \\
\hline $\mathrm{p} 53$ & $17 \mathrm{p} 13$ & Nucleus & Transcription factor & $\begin{array}{l}\text { Colon cancer; } \\
\text { lung, brain, } \\
\text { breast, bladder } \\
\text { leukemia (CML); } \\
\text { neurofibrosarcoma }\end{array}$ \\
\hline $\begin{array}{l}\text { Neurofibromatosis } \\
\text { type } 1\end{array}$ & $17 \mathrm{q} 11.2$ & Cytoplasm & $\begin{array}{l}\text { Interaction } \\
\quad \text { with p21-ras }\end{array}$ & $\begin{array}{c}\text { Neurofibrosarcoma, } \\
\text { neurofibroma }\end{array}$ \\
\hline
\end{tabular}



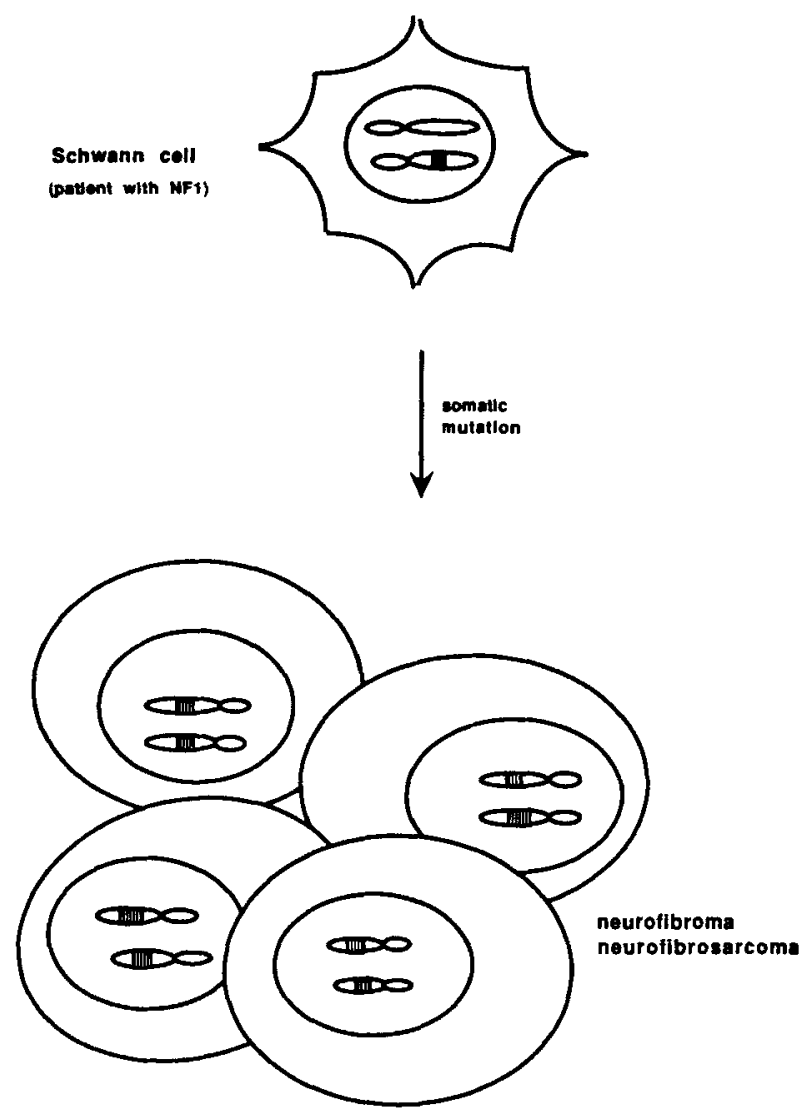

Fig 4. Illustration of the Knudson bypothesis as applied to neurofibromatoris type $I$ (NF1). In a typical Scbwann cell from a patient with NF1, one copy of the two NF1 genes bas been inberited as a nonfunctional copy (striped area of chromosome). It is pastulated that somatic mutation of the one remaining funitional NF1 gene in that Schwann cell results in loss of NF1mediated suppression of proliferation. culminating in neoplasia and the formation of neurofibromas and neurofibrosarcomas.

ras-GTP levels and reduced neurofibromin expression, perhaps as a result of mutations in the NF1 gene in these cells [26].

In normal cells the role of neurofibromin has not been established. GAP, the mammalian GTPase activating protein, is phosphorylated on tyrosine residues in response to growth factor stimulation and becomes associated with other signal transduction proteins [27]. This tyrosine phosphorylation event inactivates GAP, resulting in increased ras-GTP levels [28]. Neurofibromin, on the other hand, is phosphorylated on serine and threonine residues in response to growth factor stimulation and may become inactivated in an analogous manner to GAP (Basu TN, Gutmann DH, Collins FS, and Downward J, unpublished data). Based on the similarity to GAP, neurofibromin can be postulated to downregulate ras in the absence of growth factor stimulation but is inactivated in response to growth factors as part of a signal transduction pathway leading to ras activation and cell proliferation (see Fig 5).

The apparent ubiquitous expression of the NFl protein represents a contrast to the predominance of neural crest involvement in this disease. Recent evidence suggests that neurofibromin is expressed predominantly in brain, kidney, and spleen with detectable levels in white blood cells (D. H. Gutmann, unpublished data). Immunohistochemical analysis of adult tissues demonstrates expression of neurofibromin in central nervous system neurons, Schwann cells, dorsal root ganglia and adrenal medulla (FS Collins laboratory. unpublished results). Possibly, the tissue specificity of this disease may reflect an association between the NFl protein and other cellular signal transduction molecules that are expressed predominantly in tissues derived from neural crest.

\section{Mutations in Patients with NF1}

Examination of patients with NFl by DNA, RNA, and protein analysis is still in its infancy. To date, the following two types of mutations have been described in NF1 patients: (1) large megabase deletions in patients with NF1 and mental retardation and (2) smaller kilobase deletions, translocations, and microalterations. Large deletions involving huge stretches of DNA including the entire NFI locus have been described in patients with "classic" NF1 and significant mental retardation [29]. These deletions probably eliminate other genes involved in central nervous system development in addition to the NFI gene to account for the mental retardation. Smaller deletions and translocations interrupting the $N F 1$ gene have been reported ([4,6], Wallace $\mathrm{M}$, unpublished results; Legius $\mathrm{E}$, unpublished results). One patient with a single nucleotide mutation creating a stop codon and presumably an abnormal protein has been described [6]. Preliminary studies examining fibroblast and white blood cell lines from NF 1 parients have thus far failed to detect abnormally migrating neurofibromin proteins (Gutmann $\mathrm{DH}$, unpublished data), as was reported for dystrophin in Duchenne and Becker muscular dystrophy patients [30]. At this time, there is no clear correlation between the site of the NF1 mutation and the clinical phenotype; in fact, there is not expected to be much phenotypegenorype correlation because of the great variability in phenotype within NF1 families.

\section{Future Directions}

\section{The Role of NF1 as a Tumor Suppressor Gene}

There is still much to learn about neurofibromin and its role in tumor biology, cell growth, and development. One function of a small portion of neurofibromin ( $10 \%$ of the entire molecule) has been delineated, but it remains to be proved that the entire neurofibromin molecule can downregulate rai. What 

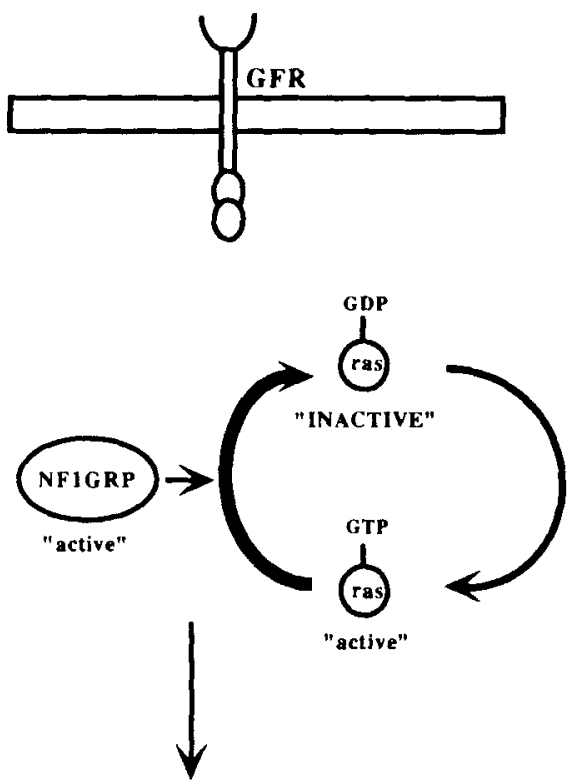

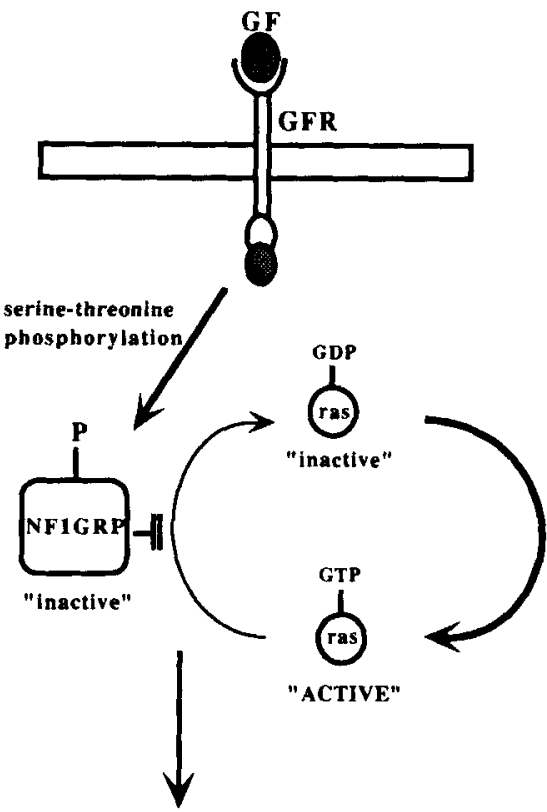

CELL PROLIFERATION
Fig 5. One possible mechanism for neurofibromin-mediated cell proliferation suppression. (A) In the resting state, neurofibromin (NFIGRP) is in the active, dephosphorylated form and accelerates the conversion of $p 21$-ras from the active guanosine triphosphate (GTP)-bound to the inactive guanosine diphosphate (GDP)-bound form (thick line). When the majority of ras is in the inactive form, there is little or no stimulation of downstream cell proliferation pathways. (B) In the growth factor (GF)stimulated state, binding of the GF ligand to its appropriate receptor (GFR) results in serinel threonine phosphorylation of neurofibromin (NFIGRP), converting neurofibromin to its inactive form. When neurofibromin is in the inactive form, ras remains in the active GTP-bound state and stimulates downstream patbways culminating in cell proliferation. Likewise, inactivation of neurofibromin by mutation in neural crest-derived tissues might result in a predominance of the active GTP-bound ras and cell proliferation.

does the rest of neurofibromin do? Preliminary results suggest that neurofibromin immunoprecipitated from cells indeed has GTPase accelerating activity (Downward J, Gutmann DH, unpublished data), but there is no proof that this is its only function within cells. The association of neurofibromin with cytoskeletal structures, such as microtubules, suggests perhaps another function for the NF1 protein. Microtubule assembly and disassembly is a GTP-dependent process; microtubules assemble and elongate when the tubulin monomer building blocks are in the GTP form and dissociate when the polymerized tubulin subunits are in the GDP form. Control of the GTP state of tubulin could be analogous to the control of ras guanosine phosphorylation because it requires both GTPase-activating proteins and guanine nucleotide-replacing proteins [31].
Dynamin, a microtubule-associated protein, was recently cloned and shown to have intrinsic GTPase activity [32]. Analysis of the predicted amino acid sequence revealed a guanosine nucleotide-binding domain distantly related to ras and other similar proteins. Dynamin appears to be involved in the bundling and tight association of microtubule filaments as well as in the transport of vesicles during endocytosis $[33$, 34]. One could postulate that neurofibromin acts as a GAP to direct cytoarchitectural changes in the cell in response to growth factors. If neurofibromin is analogous to GAP, in that phosphorylation downregulates its activity [28], then inhibition of neurofibromin's role in limiting cell proliferation through either ras and/or some interaction with microtubule elements could be envisioned to result in unlimited cell growth or transformation.

\section{NF1 Animal Models}

Much effort is being invested in several laboratories to create a mouse model for NF1 by creating a germline knockout of the NF1 gene, and the resulting phenotype will be of considerable interest. Previously, transgenic mice generated by introducing the human T-lymphotropic virus type 1 (HTLV-I) tat gene into the germline produced animals with tumors morphologically similar to neurofibromas [35]. However, the link between HTLV-I infection and NF1 remains to be established. Multiple peripheral neurofibromas were produced in hamsters after transplacental introduction of $N$-nitroso- $N$-ethylurea, but these animals 
also developed Wilms' tumors, a tumor type not seen in NF1 patients [36].

\section{DNA Diagnosis in NFI}

Now that the entire NFl gene has been cloned and sequenced, it is possible to study gene mutations in patients with NF1. The approaches taken to screen patients with NFl for mutations will necessitate a combined approach of DNA, RNA, and protein analysis. Given the high rate of spontaneous mutation in NFI and the large size of the gene, the search for causative mutations may be quite laborious. In fact, clinical application of DNA analysis in the diagnosis of NF1 is still not a reality. It is possible that mutations in different regions of the $N F 1$ gene will produce different phenotypes, as has been demonstrated for mutations within the dystrophin gene. As was true with the dystrophin gene where other related but distinct disorders may be caused by mutations within the same gene, it is important to study neurological disorders with abnormalities similar to those found in patients with NFI for alterations in the NFI gene. The ideal proof that any given DNA or protein mutation actually results in the disease will require demonstration that replacement of the wild type but not mutant NFI in NFI-deficient cells corrects the abnormal phenotype. To date, no such assay is available.

\section{Therapy}

The cloning of the NFl gene opens the door to a more complete understanding of NF1 pathobiology with the goal of designing specific, nonsurgical treatments for affected patients. The finding of elevated ras-GTP levels in tumors from NF1 patients suggests that the inability of neurofibromin to downregulate ras may have something to do with the development of neurofibromas. Rai is normally found in the cytoplasm but becomes membrane associated after the addition of a farnesyl lipid group (farnesylation). Once associated with the membrane, ras participates in events that culminate in transformation. Drugs that inhibit farnesylation have been shown to inhibit the mitogenic effects of growth factors and the tumorigenic properties of neuroblastoma cells (reviewed in [37]). More useful therapies might involve drugs that inhibit farnesyl transferase (addition of farnesyl group to the ras protein), rather than lovastatin and compactin, which block farnesyl synthesis. Further study of these and related drugs may provide useful therapies for NF1 patients.

W $\mathcal{C}^{2}$ thank the members of our neurofibromatosis research group including Drs Paula Gregory, Margaret Wallace, Susan WilsonGunn, Lone Andersen, and Douglas Marchuk, as well as our collaborators elsewhere, Drs Julian Downward, Tanya Basu, Lynn Rurkowski, Gihan Tennekoon, Richard Jove, and Mark Boguski. D.H.G. is an associate and F.S.C. is an investigator of the Howard Hughes Medical Institute.

\section{References}

1. Riccardi VM, Eichner JE. Neurofbromatosis: phenutype, natural history and pathogenesis. Baltimore: Johns Hopkins Univer. siry Press, 1986

2. Bader IL. Neurofibromatosis and cancer. Ann NY Acad Sci 1986:486:57-65

3. Goldgar DE, Green P, Parry DM, Mulvihill JJ. Multipoint linkage analysis in neurofibromarosis type 1 : an international collaboration. Am J Hum Genet 1989;41:6-12

4. Wallace MR, Marchuk DA, Andersen LB, et al. Type 1 neurofibromatosis gene: identitication of a large transcript disrupted in three NFl patients. Science 1900:249:181-186,

5. Viskochil D, Buchberg AM, Xu $G$, ee al. Detetions and a translocation interrupt a cloned gene at the neurotibromatosis type 1 locus. Cell 1990;62:18:-192

6. Cawthon RM, Weiss $\mathrm{R}, \mathrm{Xu} G$, et al. A major segment of the neurofibromatosis type 1 gene: CDNA sequence, gemomic struc: ture and point mutations. Cell 1990,(52:19)3-20)

7. Marchuk DA, Saulino AM, Tavakkol R, at al. CDNA cloning of the type 1 neurofibromatosis gene: complete sequence of the NF1 gene product. Genomics 1991;11:931-940

8. Viskochil D, Cawthon R, O'Connell P, et al. The gene encoding, the oligodendrocyte myelin glycoprotein is embedrled within the neurofibromatosis type i gene. Mol Cell Biol 19)1;11: $906-912$

9. O'Connell P, Viskochil D. Buchbery A, et al. The human homolog of murine EVI2 lies between two von Recklinghauser neurofibromatosis translocations. Genomics 1990;7:547.554

10. Cawthon RM, Andersen LB, Buchberg AM, et al CDNA sequence and genomic structure of EVI2B, a gene lying within an intron of the neuroftbromatosis type 1 gene. Genomics 1991; $9: 446-460$

11. Mikol DD, Gulchet JR, Srephansson K. The oligedendrocyte myelin glycoprotein belongs to a distinct family of proteins and contains HNK-I carbohydrate. I Cell Biol 1990;110:4? 1-479)

12. Buchberg AM, Cleveland IS, Jenkins NA, et al. Sequence homology shared by neurofibromatosis type 1 gene and IRA-1 and IRA-2 negative regulators of the RAS cyclic AMP pathway. Nature 1990;347:291-295

13. Xu G, O'Connell P, Viskochil D, et al. The neurofibromatosis type 1 gene encodes a protein related to GAP. Cell 1900;62: 599-608

14. Vogel US, Dixon RAF, Schaber MD, et al. Cloning of bovine GAP and its interaction with oncogenic rar p21. Nacure 1088; $335: 90-93$

15. 'Tanaka K, Nakafuku M, Satoh $T$, et al S. cerevisiae genes IRA I and IRA2 encode proteins that may be functionally equivalent ro mammalian ras GTPase activating protein. (ell 1900,00): $803-807$

16. McCormick F. ras GTPase activating protein: signal transmitter and signal terminator. Cell 1989;56:5-8

17. Ballester R, Marchuk D, Boguski M, ef al. The NF/ bocus encodes a protcin functionally related to mammalian (AAP and yeast IRA proteins. Cell 1990;63:851--859

18. $\mathrm{Xu} G$, Lin $B$. Tanaka $K$, et al. The catalytic domain of the neurofibromatosis type 1 gene product stimulates ras GTPase and complements ira mutanes of $\mathrm{S}$ cerevisiae. Cell 1990;63: $835-841$

19. Martin GA, Viskochil D, Bollag G, et at. The GAP retated domain of the neurofibromatosis type 1 gene proluct interacts with ras $\mathrm{p} 21$. Cell 1990;63:843-849

20. Gutmann DH, Wood DL. Collins FS. Wentification of the neurofibromatosis type 1 gene product. Pro Nat Acad Sci USA $1991 ; 88.9658-9602$

21. DeClue J, Cohen BD, Lowy DR. Identification and characterization of the neurofibromatosis rype 1 protein product. Proc Nat Aad Sa USA 1991;88:9014-9018 
22. Stanbridge EJ: Human tumor suppressor genes. Annu Rev Genet 1990;24:615-657

23. Knudson AG $\mathrm{J}_{\mathrm{r}}$. Mutation and cancer: a statistical study of retinoblastoma. Proc Natl Acad Sci USA 1971;68:820-823

24. Smith MR, DeGudicibas SJ, Stacey DW. Requirement for c-ras proteins during viral oncogene transformation. Nature 1986; 320:540-543

25. Feramisco JR, Clark R, Wong G, et al. Transient reversion of ras oncogene-induced cell transformation by antibodies specific for amino acid 12 of ras protein. Nature 1985;314:639-642

26. Downward J. Characterization of the NF1 gene product. Presented at the National Neurofibromatosis Foundation Meeting, Boston, MA, 1991

27. Moran MF, Polakis P, McCormick F, et al. Protein-tyrosine kinases regulate the phosphorylation, protein interactions, subcellular distribution and activity of p21-ras GTPase-activating protein. Mol Cell Biol 1991;11:1804-1812

28. Downward J, Graves JD, Warne PH, et al. Stimulation of p21ras upon T-cell activation. Nature 1990;346:719-723

29. Kayes I, Erlich P, Riccardi V, et al. Molecular analysis of patients with NF1-associated mental retardation and NF1 "carrier" individuals. Presented at the Narional Neurofibromatosis Foundation Meeting, Boston, MA, 1991

30. Hoffman EP, Fischbeck KH, Brown RH, et al. Characterization of dystrophin in muscle biopsy specimens from patients with Duchenne and Becker muscular dystrophy. N Engl J Med 1988;318:1363-1368

31. Hall A. ras and GAP: who's controlling whom? Cell 1990;61: 921-923

32. Obar RA, Collins CA, Hammarback JA, et al. Molecular cloning of the microtubule-associated mechanochemical enzyme dynamin reveals homology with a new family of GTP binding proteins. Nature 1990;347:256-261

33. Shpetner HS, Vallee RB. Identification of dynamin, a novel mechanochemical enzyme that mediates interactions between microtubules. Cell 1989;59:421-432

34. Scaife R, Margolis RL. Biochemical and immunochemical analysis of rat brain dynamin interaction with microtubules and organelles in vivo and in vitro. J Cell Biol 1990;111:30233033

35. Hinrichs SH, Nerenberg M, Reynold RK, et al. A transgenic mouse model for human neurofibromatosis. Science 1987; 237:1340-1343

36. Nakamura T, Hara M, Kasaga T. Transplacental induction of peripheral nerve tumors in syrian golden hamsters by $N$ nitroso-N-ethylurea. Am J Pathol 1989;135:251-259

37. Gibbs JB. Ras C-terminal processing enzymes-new drug targets? Cell 1991;65:1-4 